\title{
La Setmana de la Ciència a Secundària
}

\author{
Josep M. Fernández Novell. IES Isaac Albéniz, Badalona. imfernandeznovell@ub.es \\ Carme Zaragoza
}

És aquella setmana escolar que es porten a terme un seguit d'activitats relacionades amb la ciència, en l'espai de les aules del centre i, també, fóra d'ell. Es procura que durant aquesta setmana el contingut de les matèries de "ciència" $i$ de "lletres" es relacioni amb els diferents esdeveniments científics quotidians que ens envolten.

Tota la comunitat educativa hi participa: alumnat i professorat, personal d'administració $i$ serveis $i$ els pares i mares dels alumnes.

Per aconseguir que el nostre alumnat s'acosti a la ciència i sigui capaç de comprendre i interpretar la realitat que l'envolta els portem a Expoquímia, al Museu de la Ciència, els passem pel-lícules sobre la vida de Madame Curie o d'en Ramón y Cajal, participen a les Jornades Científiques de Badalona [1] o al Badaciència [2]... En definitiva, puntualment els portem a veure un tros de ciència o els portem aquest tros a l'aula sempre de forma excepcional. Potser cal que vegin la ciència com una cosa real i quotidiana, que siguin conscients de la implicació social que té. No es pot oblidar que els nous descobriments científics en medicina, agricultura, tecnologia, etc., ens permeten una millor qualitat de vida i un major progrés.

El passat novembre del 2004 a Catalunya es va encetar la 9a Setmana de la Ciència "Viu la Ciència" on, en paraules extretes del llibret informatiu [3, 4], "Cal posar el coneixement de la ciència a l'abast de tothom. La divulgació de la recerca és, per això, una exigència social i de país. I així ho entenem totes les institucions implicades a la 9a Setmana de la Ciència a Catalunya". Aquestes activitats acosten el món de la ciència a tota la societat.

Nosaltres vàrem traslladar aquestes idees de l'organització de la "Setmana de la Ciència" als centres de secundària.

\section{Què és "la Setmana de la Ciència" a I'IES?}

És aquella setmana escolar que es porten a terme un seguit d'activitats relacionades amb la ciència, en l'espai de les aules del centre i, també, fóra d'ell. Es procura que durant aquesta setmana el contingut de les matèries de "ciència" i de "lletres" es relacioni amb els diferents esdeveniments científics quotidians que ens envolten.

Tota la comunitat educativa hi participa, l'alumnat i professorat, personal d'administració i serveis i els pares i mares dels alumnes. S'aconsegueix ampliar els coneixements que tothom té sobre la ciència, ciència de la que tots formem una petita part.

El professorat, generalment el de les àrees científiques, és a dir de ciències naturals, física i química, matemàtiques, tecnologia $\mathrm{i}$ dels cicles formatius relacionats, ha de preparar les diferents activitats (taula 1), dirigides a tot l'alumnat del centre des de primer d'ESO fins a segon de batxillerat, passant per l'alumnat de cicles formatius i sense oblidar l'alumnat que fa els seus estudis en règim de nocturn. És molt important que també hi hagi activitats pensades perquè el propi professorat les desenvolupi i no sigui un simple acompanyant de l'alumnat en aquesta setmana. Això és pot aconseguir si prèviament s'ha pactat amb el propi professorat la realització d'alguna conferència de nivell. Aquest any sembla possible una o més sobre la figura d'Einstein; també, amb un assortit de preguntes difícils només per al professorat, un concurs d'acudits de ciència, etc.

\section{Informació als pares i mares}

S'envia informació a tota la comunitat educativa del centre. Els pares i mares, així com els tutors legals de l'alumnat, reben la següent carta: 
L'organització de la "Setmana de la Ciència" de I'IES vol posar en coneixement de tots els pares, mares i tutors del nostre alumnat les activitats que el Centre durà a terme del 14 al 18 de febrer d'enguany.

Esperem una gran participació dels nois i noies de l'Institut i, com no podia ser d'altra manera, convidem a tots els pares $i$ mares que puguin assistir a aquesta Setmana de la Ciència a venir el dimecres a la tarda (el cinema científic començarà a les 20 h) així com el divendres a l'acte de cloenda. Totes dues activitats es desenvoluparan a la Sala d'Actes.

Durant tota la Setmana esperem la presència d'algun dels mitjans de comunicació: el diari "El Punt", la Televisió de Badalona, de TVE2, que cada any s'han fet ressò d'aquesta activitat.

Atentament.

\section{Activitats dins de la setmana de la ciència}

- Sortides

- Cartells

- Pòsters científics

- Badaciència

- Observacions astronòmiques

- Globalciència

- Gimcaciència

- Sessió-Congrés

- Conferències

- Cloenda

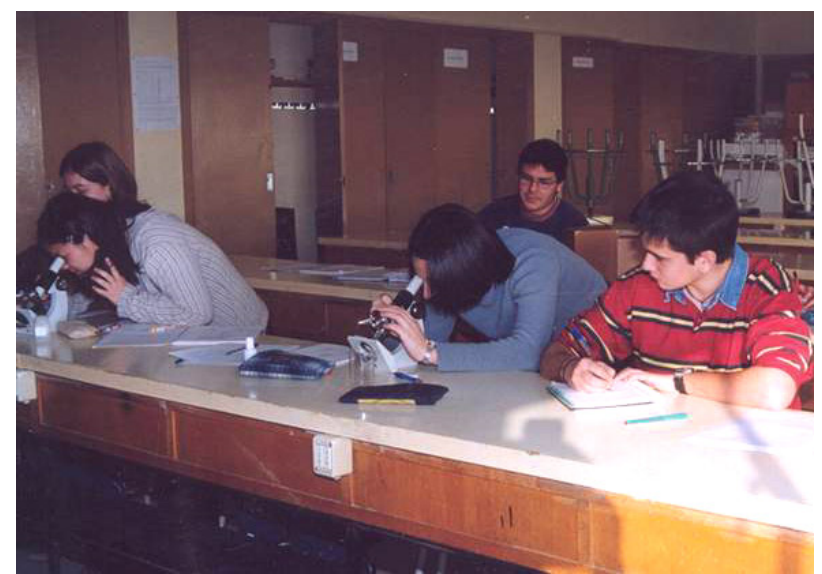

Figura 1. Alumnes treballant al laboratori durant les activitats de la Setmana de la Ciència.

\section{Detall de les activitats}

Sortides: Poden ser des d'anar al Zoo, a les mines de Súria i Cardona, al Museu de la Ciència de "la Caixa", al Museu de la Ciència i la Tecnologia de Terrassa o visitar una central d'energia, una depuradora o la fàbrica que hi ha a prop del centre.

Cartells: Com que la Setmana de la Ciència es porta a terme en el segon trimestre, això permet que en el primer, amb l'ajut del Departament de Visual i Plàstica, l'alumnat de diferents nivells dissenyi uns cartells (10 o 12) on s'anuncia aquesta setmana i que es pengen per tot el centre.

Pòsters científics: A l'entrada del centre i en alguns dels seus passadissos es colloquen pannells perquè l'alumnat hi posi, en forma de pòsters, els seus treballs científics. Els pòsters els fan de forma individual o en grups de classe ambdós tutoritzats per un professor/a de ciències i poden tractar diferents vessants: treballs d'experimen-tació i/o investigació (sempre al seu nivell), història de la ciència, biografies de científics o bé sobre el medi ambient... entre d'altres.

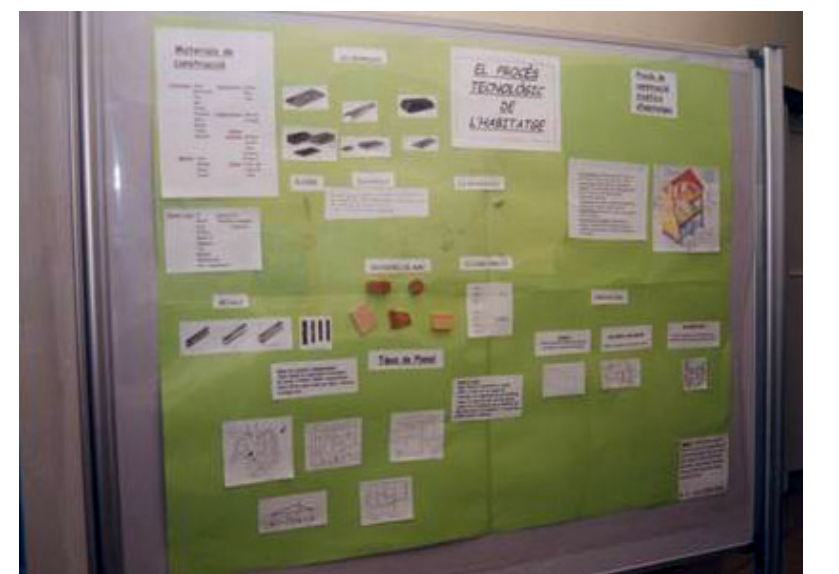

Figura 2. Un dels pòsters fets pels alumnes en el marc del congrés.

Badaciència: Programa de ràdio que consisteix en la lectura i debat de notícies de caire científic i un petit concurs de preguntes i respostes. Un grup de dos alumnes de cada classe i nivell participen en un dels programes mentre la resta de companys/es de classe/nivell els escolta i segueix el programa, omplint unes fitxes amb les preguntes, des de les pròpies classes.

Taller d'astronomia: Amb un telescopi, el matí es fa l'observació de les taques solars i a la tarda, a partir de les $20 \mathrm{~h}$, observacions directes del cel de Badalona (possibilitat de veure Júpiter i els anells de Saturn)

Globalciència: Els Seminaris de Física i Química, de Matemàtiques, de Ciències Naturals i de Tecnologia preparen una sèrie d'experiments itinerants que es desenvoluparan a totes les classes i dels quals l'alumnat ha de contestar un plec de preguntes i raonaments.

Gimcaciència: Gimcana pels laboratoris de Física i Química, Ciències Naturals, Tecnologia i Matemàtiques (aula d'informàtica) del centre adreçada a 
l'alumnat de primer cicle de secundària, on l'alumnat ha de passar una sèrie de proves.

Sessió-Congrés: A la Sala d'Actes del centre i davant la resta d'alumnat, professorat, personal administratiu i de serveis, i pares i mares, uns alumnes de diferents nivells exposen, de forma oral, els treballs científics que han fet. La sessió acaba amb una conferència.

Conferències: Un parell de conferències a càrrec d'investigadors de reconeguda vàlua (podem citar el meteoròleg badaloní Santi Parés entre d'altres) sobre temes de molta actualitat i donades a un nivell adient perquè l'alumnat els segueixi. Això fa que la participació no s'hagi de pregar.

Cloenda: En aquest acte, obert a tothom, sempre s'intenta tenir la presència d'un representant del Departament d'Educació 0 de la Regiduria d'Ensenyament que li doni un caràcter més institucional, com també representants de l'equip directiu, del professorat i de l'associació de mares i pares d'alumnes del centre i de l'alumnat (part indispensable de tota la setmana)

\begin{tabular}{|c|c|c|c|c|c|}
\hline & Dilluns & Dimarts & Dimecres & Dijous & Divendres \\
\hline $\begin{array}{l}\text { MATI } \\
9 \mathrm{~h}\end{array}$ & $\begin{array}{l}\text { Sortida } \\
\text { Parc Natural de la } \\
\text { Garrotxa } \\
\text { Coop. la Fageda } \\
\text { (Batx.) } \\
\text { Globalciència } \\
\text { (3r i 4t ESO) }\end{array}$ & $\begin{array}{l}\text { Exposició cartells } \\
\text { Què és la cièn- } \\
\text { cia? } \\
\text { Tallers: } \\
\text { Paper i sabó }\end{array}$ & $\begin{array}{l}\text { Globalciència } \\
\text { (3r i 4t ESO) } \\
\text { Observació de } \\
\text { taques solars }\end{array}$ & $\begin{array}{l}\text { Gimcaciència } \\
\text { (1r i 2n ESO) } \\
\text { Congrés } \\
\text { L'obesitat } \\
\text { Curric. ciències } \\
\text { (professorat) }\end{array}$ & $\begin{array}{l}\text { Sortida } \\
\text { Museu ciència } \\
\text { Terrassa }(2 \mathrm{n} \\
\text { ESO) } \\
\text { Taula rodona } \\
\begin{array}{l}\text { Ciència i Univer- } \\
\text { sitat }\end{array} \\
\end{array}$ \\
\hline $\begin{array}{l}\text { TARDA } \\
15.15 \mathrm{~h}\end{array}$ & $\begin{array}{l}\text { Pòsters ciència } \\
\text { (ESO i Batx) }\end{array}$ & $\begin{array}{l}\text { Badaciència } \\
\text { (1r i 2n ESO) } \\
\text { Badaciència } \\
\text { (3r i 4t ESO) }\end{array}$ & $\begin{array}{l}\text { Ciència Oberta } \\
\text { (Centres adscrits) } \\
\text { Badaciència } \\
\text { (Centres adscrits) }\end{array}$ & \begin{tabular}{|l|} 
Ciència Oberta \\
(Centres adscrits) \\
Badaciència \\
(Centres adscrits)
\end{tabular} & $\begin{array}{l}\text { Ciència Oberta } \\
\text { (Centres adscrits) } \\
\text { Badaciència } \\
\text { (Centres adscrits) }\end{array}$ \\
\hline $\begin{array}{l}\text { NIT } \\
17.30 \mathrm{~h}\end{array}$ & $\begin{array}{l}\text { Pòsters ciència } \\
\text { (Batx. nocturn) }\end{array}$ & $\begin{array}{l}\text { Badaciència } \\
\text { (Batx. nocturn) }\end{array}$ & $\begin{array}{l}\text { Astronomia } \\
\text { Observar Júpiter i } \\
\text { Saturn } \\
\text { Cinema científic } \\
\text { (Obert a tothom) }\end{array}$ & $\begin{array}{l}\text { Taller fotografia } \\
\text { (Alumnat i } \\
\text { professorat) }\end{array}$ & $\begin{array}{l}\text { Cloenda } \\
\text { Congrés } \\
\text { Treballs (Batx.) } \\
\text { Conferència: } \\
\text { Cèl/lules mare } \\
\text { (Obert a tothom) }\end{array}$ \\
\hline
\end{tabular}

Taula 1. Organització tipus d'una setmana de la ciència a l'IES Isaac Albéniz.

\section{Premis per als participants}

En les activitats on hi ha competència entre els grups com el Badaciència, es premia el grup guanyador de cada nivell (de primer d'ESO fins a segon de Batxillerat o Cicle formatiu). Mentre que en el Gimcaciència i el Globalciència es premia el millor grup de cada classe. En la resta d'activitats, sense competència, cartells, pòsters científics i en les exposicions orals de la sessió-congrés hi ha premi per a tots els participants.

Els premis, lliurats el dia 23 d'abril, Sant Jordi, en un acte especial davant tot l'alumnat, consten de llibres i samarretes amb dibuixos relacionats amb la "Setmana de la Ciència".

\section{Escoles de Primària}

Menció a part mereix la presència activa de les escoles de Primària adscrites al centre durant aquesta "Setmana de la Ciència". Aquestes escoles hi participen portant, un dia d'aquesta setmana, els seus alumnes de sisè de Primària. Prèviament aquestes han seleccionat les activitats que volen que facin els seus nens i nenes. Així uns anys prefereixen el Badaciència i l'Astronomia, adaptant-se, el primer, al seu nivell mentre que en l'astronomia gaudeixen de mirar el cel amb el telescopi. Altres anys volen realitzar les experiències que es fan als laboratoris, preparades només per a ells, amb el nom de "La ciència oberta" i d'aquesta manera poden conèi- 
xer tan el professorat com les instal-lacions del centre que compartiran l'any següent.

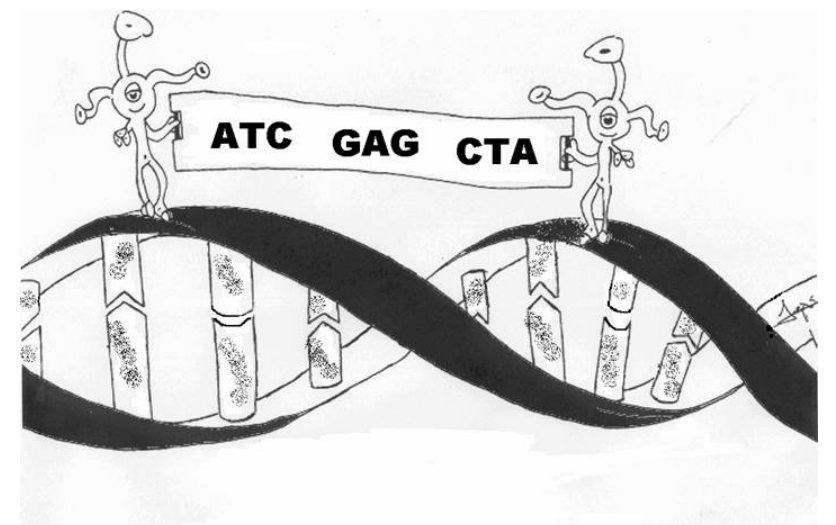

Figura 3. Dibuix fet per Jepi que es va estampar a les samarretes que es van repartir com a premi a tots els participants.

\section{Conclusions}

Aquesta activitat ajuda a ampliar la cultura científica de la nostra societat en general i especialment als diferents estaments del nostre centre com també als visitants de les escoles de primària adscrites ja que hi participen des dels pares i mares d'alumnes passant per l'alumnat i el professorat.

Esperem que aquest petit gra de sorra serveixi tanmateix per despertar i/o augmentar les vocacions científiques entre els nostres joves.

\section{REFERÈNCIES}

[1] Josep M. Fernández-Novell (2000). Les Jornades Científiques de Badalona. Perspectiva escolar, 243, 73-77.

[2] Josep M. Fernández-Novell i Carme Zaragoza Domènech (2001). "Badaciència" i "Juguem amb la ciència", programes de ràdio com a recurs didàctic. Perspectiva escolar, 252, 67-71.

[3] Fundació Catalana per a la Recerca (2004). 9a Setmana de la Ciència.

[4] www.setmanaciencia.org 